\title{
Del amor como reconocimiento, a la valentía ante la castración
}

\author{
Adam's rib | George Cukor | 1949 - Marriage Story | Noah Baumbach | 2018 \\ Eduardo Laso* \\ Universidad de Buenos Aires
}

Recibido 15 de agosto de 2021; aprobado 26 de septiembre de 2021

\begin{abstract}
Resumen
Jacques Lacan sitúa con el aforismo "No hay relación sexual", un desencuentro estructural que el amor apuesta ilusoriamente a volverlo posible. Operación soportada en la pasión de la ignorancia, que por un instante hace de la pareja la ilusión de que el destino los hizo el uno para el otro. Adam's rib de George Cukor plantea la pregunta de desde dónde se sostiene una pareja: si desde el reconocimiento mutuo en el plano de la igualdad de los sexos, o desde el reconocimiento del deseo, que introduce la diferencia y la falta. Para Lacan, el amor se pone a prueba enfrentando la castración. Si en el film de Cukor, Amanda pondrá a prueba a su esposo a que done su falta por amor, también ella será puesta a prueba por Adam a que acepte que más allá de la militancia por la igualdad de derechos femeninos, en el plano erótico se requiere la admisión de una "pequeña diferencia". Diferencia que no es lo mismo planteada a nivel imaginario o real. El reconocimiento en el plano imaginario reanuda la separación y unión hasta el infinito, a menos que se inscriba como falta real que abra a una nueva forma de amor, más curado de las pasiones del ser. En estas comedias de rematrimonio las parejas pasan dos veces por la decisión de elegirse, en una suerte de topología del ocho interior propia del acto logrado: el corte a la fijación a un objeto de goce que obturaba la castración, relanzando así el deseo amoroso.
\end{abstract}

Palabras clave: feminismo $\mid$ deseo $\mid$ diferencia sexual | matrimonio

From love as recognition, to courage in the face of castration

\begin{abstract}
With his dictum "There is no sexual relationship", Jacques Lacan places a structural disagreement that love illusory bet to make it possible. Supported in the passion for ignorance, for an instant this operation creates to the couple the ilussion that destiny made one to each other. George Cukor's Adam's rib raises the question about from where does the couple holds: if it is from mutual recognition in the level of sexual equality, of from the recognition of desire that introduces difference and lack. For Lacan, love is tested by facing castration. If in Cukor's film, Amanda will put her husband to the test of offering his lack for love, she too will be put to the test by Adam to recognize that beyond the militancy of equal rights for women, it is required to admit in the erotic level a "tiny difference". Difference that is not the same raised on an imaginary or on a real level. In the imaginary level, the admition renew the the cycle of separation and union of the couple to infinity, unless it is registered as a real lack that opens to a new form of love more cured from the passions of being. In this remarriage comedies, the copules go through the decision to choose each other twice, in a sort of inner eight topology, proper to an accomplished act: cutting the attachment to an object of joy that seal off castration, so as to relaunch love desire.
\end{abstract}

Keywords: feminism | desire | sexual difference | marriage

\section{Screwball comedies \& comedias de rematrimonio}

En una escena de Marriage story (Noah Baumbach, 2018), al concluir la entrevista de divorcio con el abogado, Charlie Barber recoge sus papeles de un sillón, y durante unos segundos vemos un almohadón con un texto bordado que reza "Eat, drink and remarry" ("Coma, beba y recásese"). Se trata de una referencia irónica al libro de Stanley Cavell (1999) La búsqueda de la felicidad, en el que el filósofo norteamericano trabaja siete comedias clásicas de Hollywood con un motivo común: una pareja se separa... para luego volver a elegirse y estar junta. ${ }^{1}$ Se trata un tipo de comedias que llama "de rematrimonio", y las ubica como un subgénero de las screwball comedies ("comedias de enredos"), de la que La costilla de Adán de George Cukor es un ejemplo paradigmático. Que el film de Noah Baumbach ironice con el "rematrimonio", nos indica la distancia que hay entre aquella comedia de los años ' 40 y la tragedia del amor que propone Marriage story, en la que no habrá ningún remarriage.

El título del film de Cukor alude al mito bíblico del Génesis en el que luego crear al primer hombre, Javhé

* lasale_2000@yahoo.com 
vio que no era bueno que estuviese solo. Así que durmió a Adán y le sacó una costilla para hacer a Eva, la primera mujer. Jacques Lacan sugiere que la libra de carne con que se creó a Eva seguramente debió obtenerse de más abajo. Dios padre interviene castrando al varón para producir no un semejante, sino un ser de Otro sexo, heterós, mujer. Y será Eva la encargada de sacar a Adán del estado de inocencia -es decir, de la ignorancia- al tentarlo a comer el fruto de la ciencia del bien y del mal, luego de haberlo hecho ella misma. La mujer cumple en el mito la función de sacar al hombre del estado de ignorancia sobre la sexualidad, al encarnar la diferencia sexual, excepción a la lógica fálica. Hacer de soporte imaginario de la castración, encarnar la Otredad para el hombre, volvió a las mujeres el objeto de todas las pasiones masculinas, desde las amorosas o sublimadas, hasta las posesivas, segregativas o vengativas.

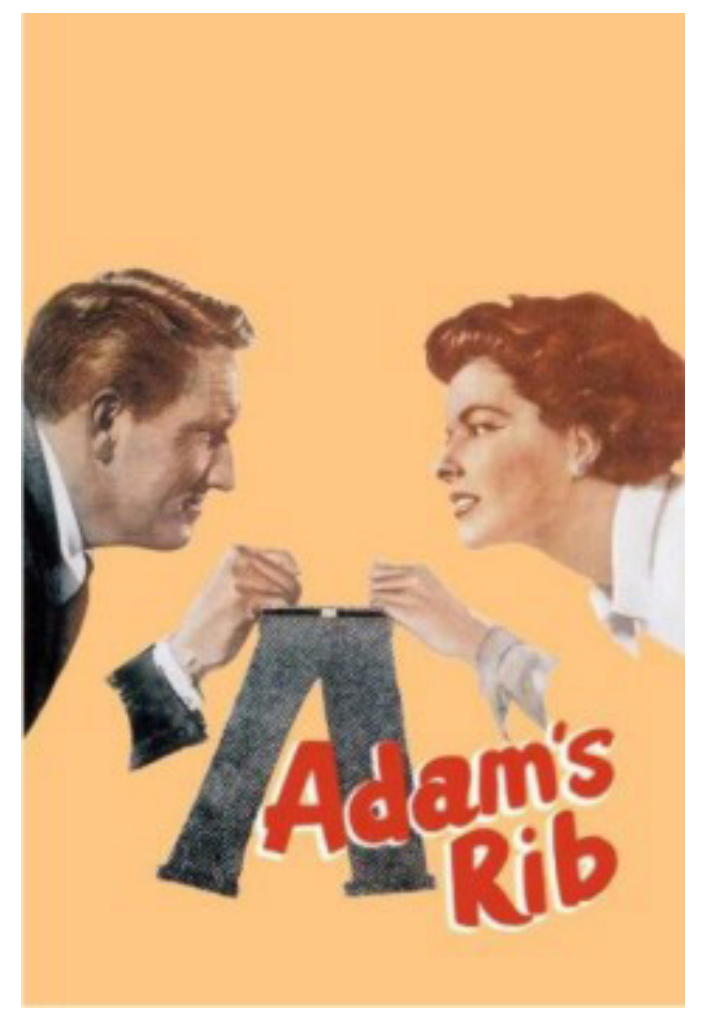

La screwball comedy es un género de comedia romántica que fue popular en EE.UU. durante la Gran Depresión de los años ‘30 y alcanzó su culminación durante la década del '40. En ellas es satirizada la típica historia de amor mediante una guerra entre los sexos en la que una mujer dominante desafía a un varón en su masculinidad. Dentro de estas comedias, Stanley Cavell (1999) identifica un subgénero que nombra comedias de rematrimonio, en las que una pareja se separa, para que transcurrida una serie de peripecias, se vuelvan a unir. Según el autor, estas comedias se proponen resolver el problema planteado por el dramaturgo noruego Henrik Ibsen (1879) en su obra Casa de muñecas. En aquel célebre drama teatral, cuando Nora descubre que su matrimonio se sostiene al precio de renunciar a sí misma, se va de su casa de un portazo. Las comedias de rematrimonio proponen una respuesta al problema: dado que la condición para que Nora vuelva al hogar es que su esposo cambie su posición ante ella, estas comedias plasman justamente el milagro por el cual el cambio se produce y la pareja separada se une nuevamente.

El planteo filosófico de Cavell (1999) alcanza un límite que podríamos calificar de propiamente hegeliano: para el autor en estas comedias se conversa todo el tiempo porque se trata una batalla por el reconocimiento entre hombres y mujeres. Un reconocimiento que, de alcanzarse, llevaría a la reconciliación, el perdón genuino y la consecución de una nueva perspectiva de la existencia. Se trata para Cavell del problema del deseo de reconocimiento, cuestión narcisista e ilusoria en la que la batalla de los sexos se haría interminable en pos de alcanzar la irrealizable unión del ser al ser.

En determinado momento, Cavell toca una cuestión que consideramos más ajustada al problema, cuando señala:

La unión de lo sexual y lo social se denomina matrimonio. Algo a todas luces inherente a la empresa del matrimonio causa problemas en el paraíso, como si el matrimonio, en sí mismo una ratificación, estuviera necesitado de ratificación. De modo que el matrimonio conlleva una decepción; llamémosla la imposibilidad de domesticar la sexualidad sin desalentarla, o su estupidez ante el enigma de las relaciones íntimas, que repelen allí donde atraen, o ante el enigma del éxtasis, que es violento al mismo tiempo que tierno, como si el leopardo hubiera de yacer con la oveja. Y la decepción busca venganza, una venganza, como si dijéramos, por haberle hecho comprender a uno que es incompleto, transitorio, que está sin hogar. (1999, pp. 40-41).

Modos en que el filósofo se aproxima al problema que Jacques Lacan sitúa con el aforismo "No hay relación sexual", siendo el amor un modo de velar la castración.

"No hay relación sexual" sitúa un real imposible de simbolizar, un desencuentro estructural que como tal "no cesa de no inscribirse", pero que el amor apuesta ilusoriamente a inscribir para volverlo posible. El encuentro amoroso plantea la suspensión de la imposi- 
bilidad mediante la captura a una imagen o la sutura de la falta del sujeto a un significante de aquel que deviene objeto de amor. Encuentro azaroso que, en tanto contingente, pasa a "cesar de no escribirse": el encuentro contingente es efectivamente escribible en tanto el encuentro a una imagen fascinante o a un significante que porta el objeto de amor con el cual suturar la propia falta. Lacan señala la verdadera naturaleza de este encuentro:

La contingencia, la encarné en el cesa de no escribirse. Pues no hay allí más que encuentro, encuentro, en la pareja, de los síntomas, de los afectos, de todo cuanto en cada quien marca la huella de su exilio, no como sujeto sino como hablante, de su exilio de la relación sexual. (1981, p. 175)

El amor pretende pasar de lo imposible de escribir la relación sexual, a algo inscribible en el destino del sujeto, que en el fondo es del orden del encuentro azaroso. El paso lógico siguiente es que ese amor que advino desde la contingencia, devenga a su vez necesario, al desplazar la negación del "cesa de no escribirse" al "no cesa de escribirse", suspendiendo la imposibilidad y reemplazando la contingencia por el destino y la eternidad del amor, amor para siempre más allá de la muerte. Operación soportada en la pasión de la ignorancia, que por un instante hace de la pareja la ilusión de que el destino los hizo el uno para el otro. El "estaba escrito" en el gran Otro.

En el seminario Aún, Lacan (1981) juega con el significante alma para decir que en el amor, se "alma" al otro. Lo que se ama es ese agalma socrático que hace al ser del otro; ese "algo" en el otro que hace que se lo ame. Sólo que la relación del ser al ser en el amor, predicada de Aristóteles al cristianismo, es sólo la ilusión de una relación armónica que intenta velar la no relación sexual. De ahí que Lacan señale que "es imposible que el sujeto no desee no saber demasiado en lo tocante a este encuentro eminentemente contingente con el otro. Por eso, del otro pasa al ser prendido a él” (pp. 175-176). Para el sujeto, sostener un manto de ignorancia doble respecto del azar del encuentro con el otro (que se pretende necesaria destinación del uno al otro) y respecto de la imposibilidad de hacer Uno con el otro, le permite la ilusión del amor en torno de un supuesto "ser" del otro. Lacan señala que el ser se dice, se sostiene en el decir, y como la palabra erra, es equívoca, se desvía, el ser también erra y es equívoco. ${ }^{2}$

Abordar el ser ¿no estriba en esto lo extremo del amor, el más grande amor? Y el más grande amor -es claro que no lo descubrió la experiencia analítica, su reflejo se percibe muy bien en la modulación eterna de los temas sobre el amor- el más grande amor acaba en el odio. (Lacan, 1981, p. 176)

Es que la ilusión de la pasión amorosa del ser al ser no puede sino terminar frustrada al toparse con lo imposible de hacer de dos, Uno.

Cavell (1999) ubica en el eje del conflicto de las remarriage comedies al divorcio -y no por ejemplo, a la infidelidad-introduciendo así la cuestión de la legitimidad del matrimonio. Creo que más bien se trata de lo que hace límite al deseo de estar con el otro y la pregunta de desde dónde se sostiene una pareja: ¿se sostiene desde el deseo de reconocimiento mutuo o desde el reconocimiento del deseo? ¿Desde la diferencia o desde la igualdad? ¿Desde el goce sexual o desde el amor? ¿ $\mathrm{O}$ tiene como condición el reconocimiento de la castración?

Para Lacan, el amor se pone a prueba enfrentando la castración:

¿No es acaso con el enfrentamiento a este impasse, a esta imposibilidad con la que se define algo real, como se pone a prueba el amor? De la pareja, el amor sólo puede realizar lo que llamé, usando cierta poesía, para que me entendieran, valentía ante fatal destino. (1981, p. 174)

$\mathrm{Y}$ en ese punto se pregunta si se trata de valentía o de los caminos de un reconocimiento. Reconocimiento y valentía no constituyen vías equivalentes. El reconocimiento es el esfuerzo de que la relación sexual que no cesa de no inscribirse por imposible, cese de no inscribirse en tanto contingencia, en el encuentro ilusorio con el otro que encubra la falta. Vía que de persistir, está condenada al pasaje del más grande amor al más grande odio, por ser una vía destinada al fracaso. La valentía del amor en cambio, implica soportar la división irremediable, el desencuentro de los dos saberes inconscientes que no se recubren. Encuentro con lo real de la castración.

\section{La costilla de Adán}

George Cukor fue uno de los grandes realizadores de Hollywood de la época dorada. Aclamado como gran director de actrices, Adam's Rib es considerada una obra cumbre de la comedia de enredos matrimoniales. Posiblemente la belleza de la película radique en el modo como somos llevados a ser testigos de la intimidad cotidiana de una pareja que se ama y desea, encarnada por Spencer Tracy y Katherine Hepburn, quienes en ese momento eran pareja en la vida real. 
Al inicio del film, asistimos al drama de Doris Attinger, una atribulada esposa y madre que intenta torpemente matar a su marido, luego de descubrirlo en compañía de su amante. Una vez detenida y encarcelada, designan como fiscal del caso a Adam Bonner, esposo de Amanda, una abogada y feminista militante, quien a su vez tomará la defensa de Doris. En su análisis del film, Cavell (1999) se pregunta por qué Amanda toma la defensa Doris cuando se entera que su marido será el fiscal. Interpreta el conflicto de los Bonner en términos de la ruptura de un pacto implícito por el cual ella no lo enfrenta profesionalmente, a cambio de que él la apoye en sus convicciones feministas. Como Amanda siente que Adam rompió ese acuerdo al aceptar un caso por el que previamente habían discutido, decide enfrentarlo profesionalmente. Y se valdrá del espacio del juzgado para que se sepa que en la intimidad tiene los mismos derechos y autoridad que su marido, a la vez que pretende que su marido la reconozca públicamente. Se trata aquí de la lectura hegeliana del deseo de reconocimiento. Pero no es tan seguro que el conflicto se juegue en el plano de la reivindicación del derecho femenino al trato igualitario y a la legítima defensa contra el maltrato masculino.

En la mañana previa, vemos a los Bonner desayunar en la cama. Amanda le pregunta al pasar por unos ruidos que Adam hizo a la noche mientras dormía. Se pregunta qué soñaba, al punto de emitir gemidos que evocan la excitación sexual. Él dice no saberlo. Por lo que sigue, podemos conjeturar que Amanda supone que él lo sabe pero lo calla. A lo largo del film iremos descubriendo que Adam se hace el distraído para evitar conflictos con Amanda.

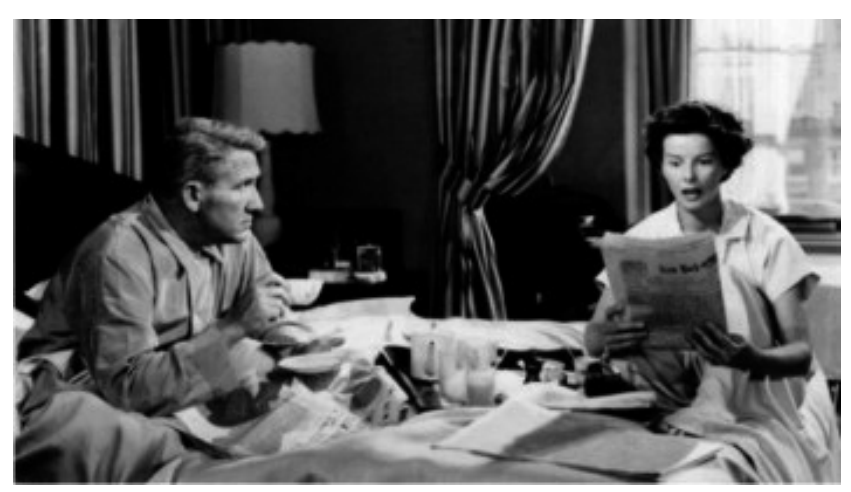

La lectura de los titulares del diario, que parecen un cambio de tema, son en verdad su continuación: Amanda lee la noticia de que una esposa disparó a su marido en presencia de su amante, y comenta gozosa: "Se lo merecía, el pequeño traidor". Lo cual inicia un debate aparentemente legalista en torno del empleo de la violencia contra la infidelidad matrimonial. O sea, el derecho o no al ejercicio de un acto fuera de la ley, así como la infidelidad está fuera de la ley del contrato matrimonial. Pero la respuesta de Amanda ("se lo merecía") es una interpretación al "no sé" de los ruidos nocturnos de Adam, quien va a seguir haciéndose el distraído, diciendo que no aprueba que la gente ande por ahí con revólveres cargados. "Depende contra quien lo usen", replica Amanda en una clara indirecta a él, en caso de que ande soñando infidelidades.

La discusión es interrumpida por la mucama, pero proseguirá escalando y adquiriendo otras formas en escenas posteriores. El drama de los Attinger (celos, infidelidad, justicia por mano propia) se instala para los Bonner como el contenido manifiesto de una pelea por la igualdad de los sexos ante la ley, que encubre el contenido latente de la cuestión de la infidelidad y el deseo sexual, presente por ejemplo, en la oportuna presencia de Kip, un músico vecino de la pareja que no cesa de manifestarle a Amanda su deseo y admiración, pero que Adam no se toma en serio.

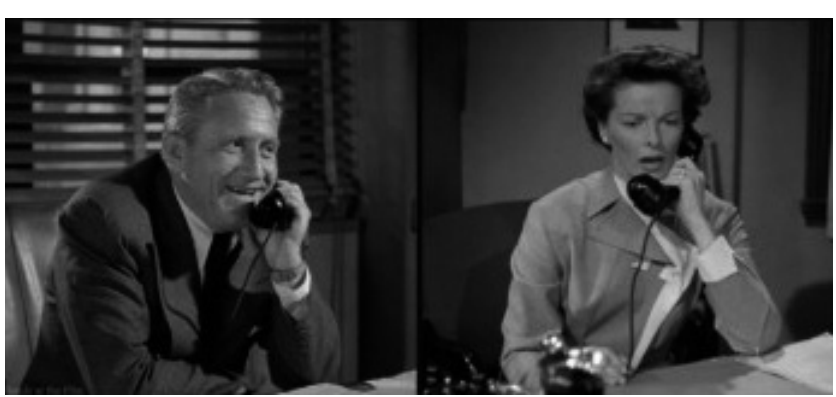

Mientras Adam es designado fiscal del caso motivo del debate con su mujer, Amanda en su oficina sigue reflexionando sobre el tema de la infidelidad. Comprueba que en el imaginario social es menos tolerable la infidelidad femenina que la masculina. Es en este contexto que Adam la llama para avisarle que su jefe le asignó el caso Attinger porque quiere una sentencia rápida, pero que le va a pedir que lo saque "para mantener la paz del hogar". Este alarde de Adam, sumado al comentario condescendiente hacia ella, la saca de las casillas. Adam se ríe y le dice que se oye simpática cuando lucha por una causa. Amanda siente que el marido la está gozando. Es, a su decir, "la gota que rebasó el vaso de una mujer". Así que va a defender su causa bajo la forma de la causa femenina, encarnada en el caso de Doris Attinger, a quien representará como abogada para ir contra Adam. 


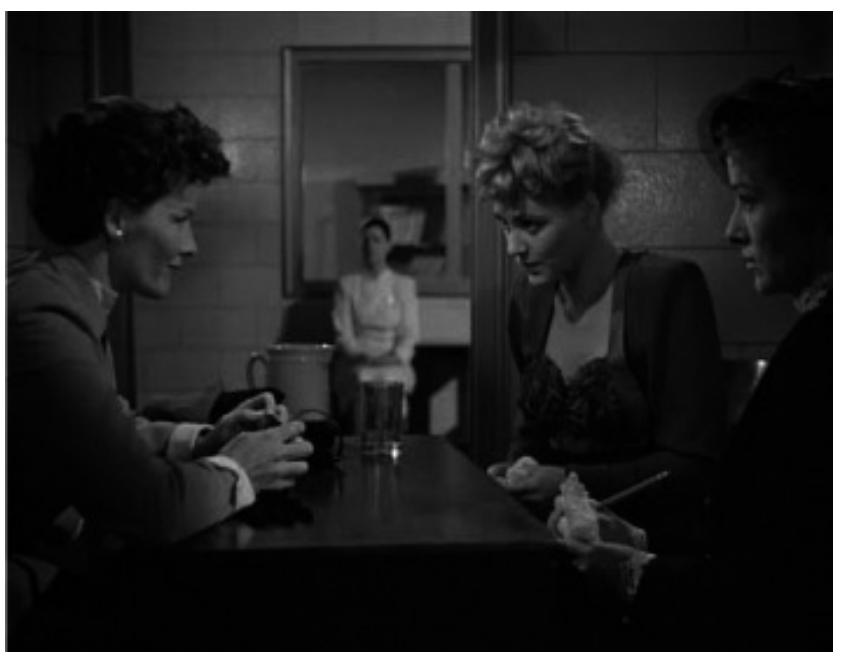

Los Attinger son el contrapunto inquietante de la pareja que forman los Bonner. Warren es un infiel consuetudinario que destrata, insulta y golpea a su esposa Doris, mientras ella tolera sus maltratos entre gritos y protestas, en una posición sumisa a la autoridad de este hombre patético. Cuando Adam entreviste a Warren en cumplimiento de su tarea de fiscal, se mostrará hosco y molesto de tener que lidiar con un sujeto del que en el fondo piensa que es responsable haber desatado la ira de su esposa. Amanda por su lado entrevistará a Doris, para encontrarse con el tipo de mujer que ella ciertamente no es ni podría ser. Si llegó a la entrevista identificada al ideal combativo del derecho de la mujer a no tolerar ser engañada por su esposo, se encuentra, por el contrario, con una mujer que viene sosteniendo las infidelidades y goza del maltrato y la sumisión al marido. Al punto que a Amanda se le vuelve incomprensible por qué alguien que viene hace casi 10 años sosteniendo una posición masoquista ante el esposo, de pronto trate de matarlo. Cuando le pregunta cuándo empezó a sospechar que estaba perdiendo el afecto de su esposo, Doris responde: "cuando dejó de pegarme". Golpes y escapadas forman parte de la vida cotidiana de esta esposa y madre de tres hijos. Si para Amanda la "gota que derramó el vaso" fue el pavoneo condescendiente de Adam, para Doris no fue la dosis cotidiana de desprecio e infidelidad que el marido le dispensa, sino la amenaza de quedarse sin esa dosis. Mientras que los maltratos aseguraban la continuación del vínculo, su ausencia de cuatro días seguidos en cambio implicaba la amenaza de una ruptura. Doris es un escándalo para el feminismo bienpensante de Amanda. Ella palpa así uno de los límites del feminismo de la igualdad. La demanda de igualdad entre los sexos se topa con el límite del goce, el erotismo y la diferencia encarnada en los cuerpos eró- genos. Llevada la demanda de igualdad al extremo del plano erótico, deviene ideal de indiferenciación entre hombres y mujeres. Una regresión a la posición de la fase fálica infantil (Ritvo, 2019). En Mujeres en movimiento, Graciela Musachi señala que el derecho humano de las mujeres a no ser sometidas a violencia tiene el límite inhumano y singular de hacerse pegar en aquellas que lo logran. Es que el síntoma puede perfectamente devenir el soporte de la vida de un sujeto, algo cuya falta haría vano el universo (Musachi, 2012).

Para hacer suyo el caso Doris, Amanda tendrá que encontrar el modo de transformar la pérdida de goce masoquista como motivo del intento de asesinato, en una amenaza a la integridad de la familia, argumento más pasable en la opinión pública. El motivo de que hay hijos de por medio viene a darle a la abogada un marco de justificación que encubre el goce de su defendida.

Para Amanda, el caso Doris es su causa, pero... ¿qué la causa a Amanda? Se trata de una "causa" en torno de la igualdad de los sexos, que conecta con aquello que la causa en su deseo por Adam: la instalación de un conflicto que perturbe la igualdad para dar entrada a la "pequeña diferencia”. Para Amanda, se trata de dramatizar en el estrado una injusticia dirigida a la sociedad patriarcal y también al marido. Acting que convoque a Adam a que, por amor, condescienda su machismo al amor por ella. Que le ofrezca su castración.

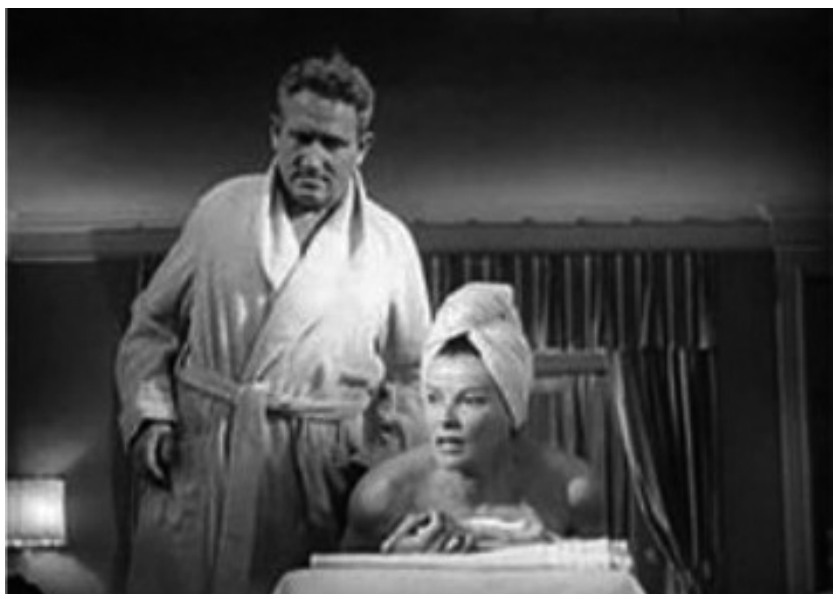

Bajo el universal del "para todos", ella lucha contra el Uno de excepción del macho gozador, del que el Sr. Attinger y Adam mismo serían sus encarnaduras, para dar lugar a la inscripción de que No existe un Uno de excepción. La sonora "palmadita" que Adam le propina a Amanda en el curso de un masaje representa para ella la verificación de que, agazapado bajo formas amables, está ante el típico varón brutal que descarga su furia contra la mujer, igual que el Sr. Attinger con 
Doris. Como respuesta, llena la corte de mujeres destacables para probar que la mujer es igual al hombre y de paso poner a Adam en ridículo haciéndolo levantar por los aires por una acróbata. Pone así a prueba a Adam como marido, sometido a una humillación pública en su dignidad.

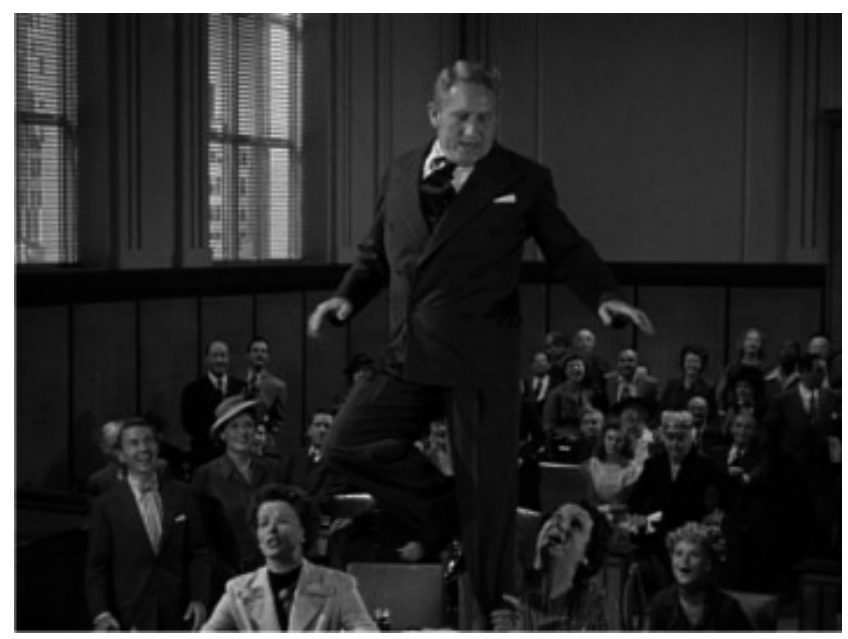

Para Cavell (1999), se trata de una batalla de los sexos por el reconocimiento de la mujer. Pero lo que sigue a la escena del ridículo abre a otra hipótesis. Luego de ese episodio, Adam ya no quiere hablar más con ella. La acusa de despreciar la ley, y que como el matrimonio es la ley, entonces desprecia también la relación que tienen y a él mismo. La línea argumentativa no es muy consistente. Amanda no niega la legalidad del matrimonio, al punto de emplearlo como argumento en el estrado: es tan sagrado, que justifica el empleo de un arma si se trata de proteger dicha institución. Adam en su rabieta, aplana el vínculo matrimonial al plano contractual. Pero luego Adam agrega algo que apunta a la verdad de aquello que aborrece y lo angustia: " $;$ Me gusta que haya dos sexos! No me gusta estar casado con lo que llaman una nueva mujer. Quiero una esposa, no una rival. Si quieres ser masculina, no lo hagas conmigo". Adam ha sido herido en su imagen viril. La dramatización de la igualdad hecha por Amanda es una demostración de que está castrado. Ella se ha tornado para él en una mujer fálica y viril, por lo que huye de la casa con un portazo. Si ella es varón, entonces él queda feminizado.

En su alegato final en el estrado, Amanda va a plantear la igualdad de los sexos. La ley "no matarás" es un universal "para todos". Pero luego agrega que los hombres han matado por fuerza mayor, en defensa propia o de su hogar, y que por ello fueron absueltos. Introduce así la excepción que confirma la regla, un "hay uno que no", en el que se hace excepción por defensa propia o fuerza mayor, pero que combina con un argumento sexista: se hace valer tal excepción para el caso de los varones por razones de género. Introduce así una ley no escrita que apoya al hombre que protege su hogar por cuestiones de género, y pide que la apliquen a Doris como esposa maltratada que actuó en defensa de su familia. La argumentación es falaz, dado que la inimputabilidad por defensa propia no es sexista, y requiere de condiciones que no aplicarían en el caso de Doris. Para reforzar los argumentos, Amanda agrega que cada ser viviente es capaz de atacar si se lo provoca suficientemente. El argumento combina así la ley escrita del "para todos" ("No matarás") y sus excepciones y una "no escrita" que es particularista y lógicamente anterior a la ley. La escrita contempla la excepción por causa justa o legítima defensa. La no escrita propuesta por Amanda es en cambio el derecho a atacar violentamente ante una provocación. Se trata de un exceso que introduce un más acá de la ley escrita: la capacidad de atacar ante una provocación es una cuestión que no es legal; un exceso que la ley intenta acotar.

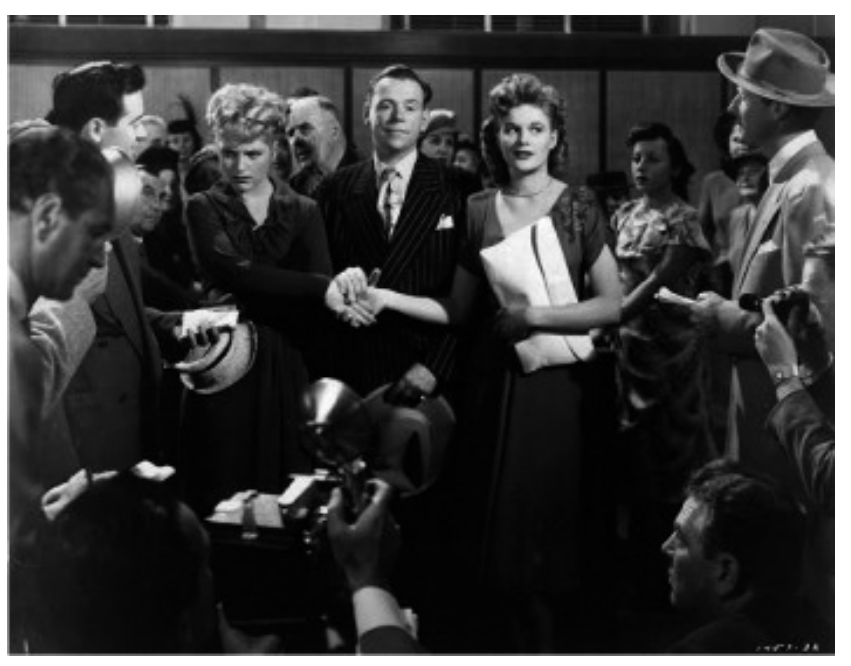

Este goce no regulado por la ley, que se presenta como un exceso que Amanda esgrime como derecho, es lo que a Adam lo angustia. En su alegato, pierde el hilo tratando de argumentar que la dramatización de Amanda no tiene nada que ver con el proceso que allí se juzga. Pero pierde el caso y Doris es declarada libre de culpa y cargo. En un giro irónico, Doris y su marido se reconcilian. Y se sacan fotos para los periodistas, en las que aparecen junto a los hijos y la amante de él. Es que la infidelidad y el maltrato son para Doris perfectamente tolerables. Puede haber rematrimonio no soste- 
nido desde el amor ni desde los ideales de emancipación femenina e igualdad de los sexos, sino desde el desprecio mutuo, para sorpresa de la idealista Amanda (y de Stanley Cavell). En cambio, Adam y Amanda han roto su matrimonio.

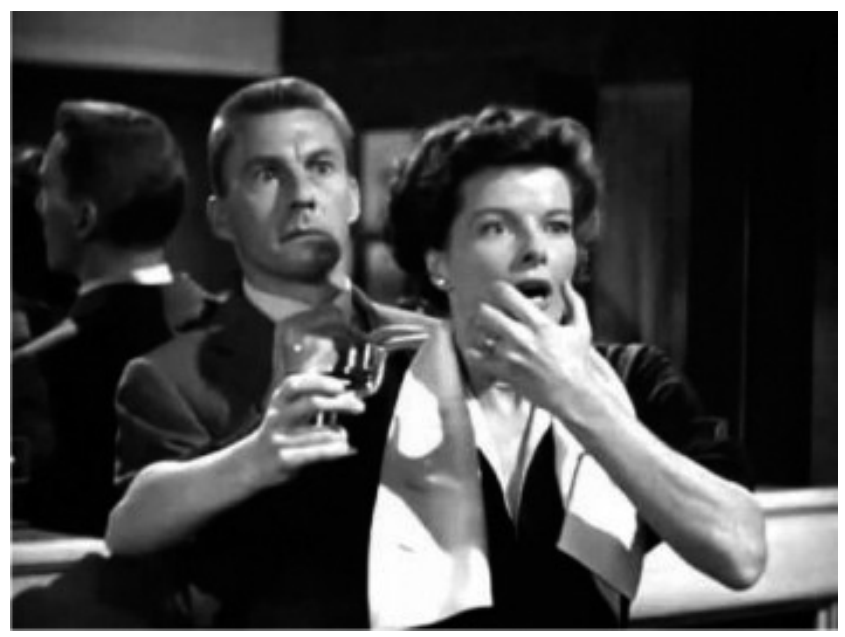

Esa noche, Amanda reflexiona en el departamento de su amigo Kip acerca de si es o no "dominante", vale decir, masculina. Adam va entonces a simular para ella la escena de Doris con su marido y la amante, aquella escena violenta fuera de ley, para devolverle su propio mensaje en forma invertida. Irrumpe en el departamento de Kip con una pistola de juguete para amenazarlos. Logra así que ella admita que nadie tiene derecho a quebrantar la ley por mano propia. De ese modo, Adam consigue empatar con Amanda. Que para el caso es reconducirla al redil de la lógica fálica. Sólo que ese empate los iguala y no permite revincularlos como hombre y mujer.

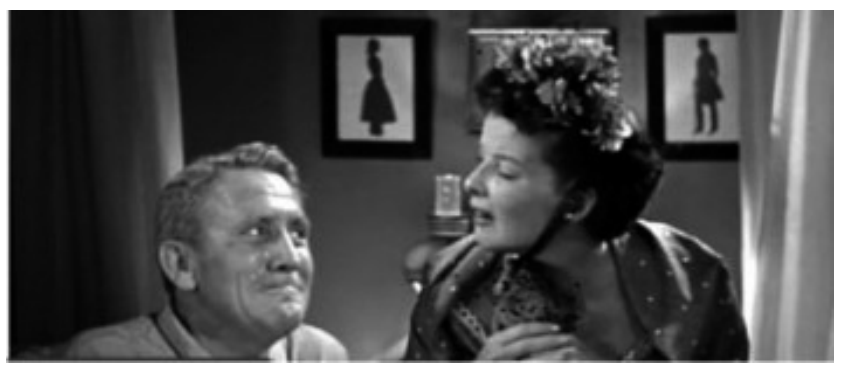

Para ello, Adam tendrá que llorar ante la pérdida de la casa de campo que simboliza el vínculo entre ellos, convocando a la ternura de Amanda. Si Adam recupera a Amanda, es por su capacidad para hacer una simulación de llanto, con lo que la conmueve y así la recupera como mujer. Si ella logra feminizarlo, él también la feminiza a ella, y al hacerlo, la vuelve deseable para él. Amanda le dice que eso demuestra que no hay diferen- cia entre los sexos, que también los hombres pueden llorar y ocupar una posición femenina. Que en el fondo no hay un Uno de excepción: todos estamos castrados. Pero entonces agrega que quizás haya una diferencia, pero "es muy poca diferencia". Sólo que ese poco de diferencia es el trasfondo del sostén del erotismo. Ocasión para que Adam recupere su posición viril al grito de ; Vive la différence! Estamos ante la dimensión cómica, que para Lacan es el triunfo del falo ${ }^{3}$.

Para Lacan, el carácter fatal del amor es consecuencia de la conjunción de dos saberes inconscientes que no se recubren, ya que son intrínsecamente distintos. Pero cuando se recubren "esto constituye una sucia mezcolanza” (Lacan, 1974, s.d.). Podríamos ensayar un diálogo en esta pareja, que plasme la "sucia mezcolanza” en que están atados:

Amanda: Tú eres un varón engreído que se pretende superior por creer detentar el falo. Te pido que por amor me dones tu falta.

Adam: Tú te posicionas como una mujer viril que pretende detentar el falo, lo cual me impotentiza. Te pido que te feminices para poder desearte.

Amanda: Todos somos iguales ante la castración y no existe un Uno de excepción no castrado. Pero por amor a ti, te otorgo una pequeña diferencia, en tanto te elevo a Uno único, y hago de tu pene el falo con el que gozo fálicamente.

\section{Adam: ; Vive la différence!}

Sólo que esta diferencia es planteada aquí como imaginaria. Queda a cuenta para Amanda el goce suplementario o femenino, en la medida que asuma la falta en ser y la falta del Otro. Lo que supone salir de la reivindicación de igualdad en el plano del goce sexual. Aceptar un No-Todo fálico y que la diferencia no es imaginaria ni pequeña, sino real.

El triunfo de la diferencia en el plano imaginario inevitablemente reanudará la guerra entre Adam y Amanda, luego del paréntesis de intimidad sexual con la que se cierra la película. Lo que abre a la pregunta de si esta repetición de separación y unión rematrimonial no proseguirá hasta el infinito, y cuál sería la condición de que el ;Vive la difference! no opere en el registro imaginario sino como nueva forma de amor, más curado de las pasiones del ser.

Si el amor es el lazo entre dos saberes inconscientes, podríamos representarnos topológicamente estos dos saberes como dos toros enlazados: 


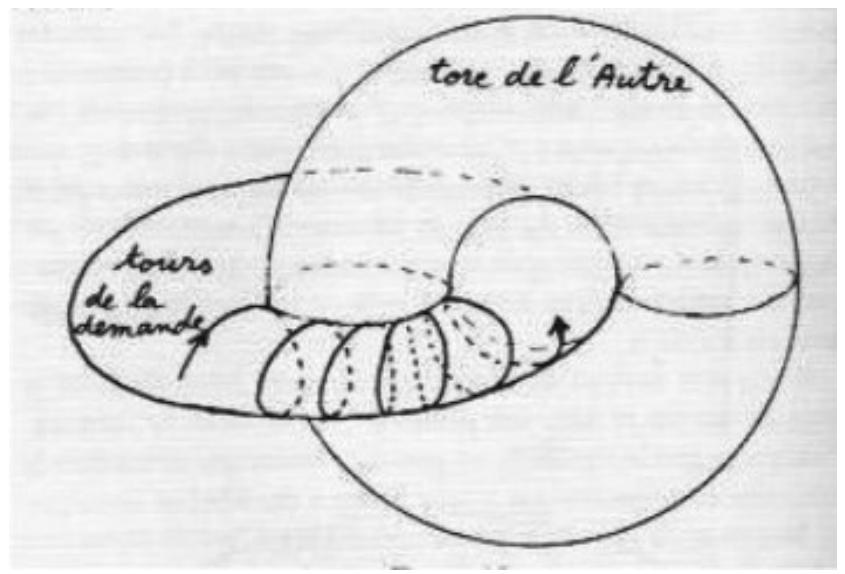

Las vueltas de la demanda dirigida al Otro arman un circuito que no cuenta la falta del Otro, el vacío central que los enlaza, y que queda cubierto por la demanda de cada partenaire. Es la vía del no cesa de escribirse, en la demanda de reconocimiento: pasión de la ignorancia dirigida al ser del Otro que encubre su falta en ser, representada por el agujero central. El único circuito que permite la cuenta de esa falta es el 8 interior, que enlaza tanto el vacío del sujeto como la falta del Otro. La vía de la valentía ante la castración.

Las comedias de rematrimonio plasman la estructura topológica de lo que requiere un acto logrado, en tanto supone la estructura de un ocho interior que pase dos veces por el mismo punto vacío. Las parejas en estas comedias pasan dos veces por la decisión de elegirse, sólo que se trata de que inscriban la falta en ser. El acto logrado para Lacan tiene la estructura topológica de un ocho interior por el cual se inscribe la vuelta por la falta del Otro para poder producir un corte, separando así el objeto a y el sujeto. El acto no es la separación del otro, sino el cor- te con cierta fijación a un objeto de goce que obturaba la castración, relanzando así el deseo amoroso.

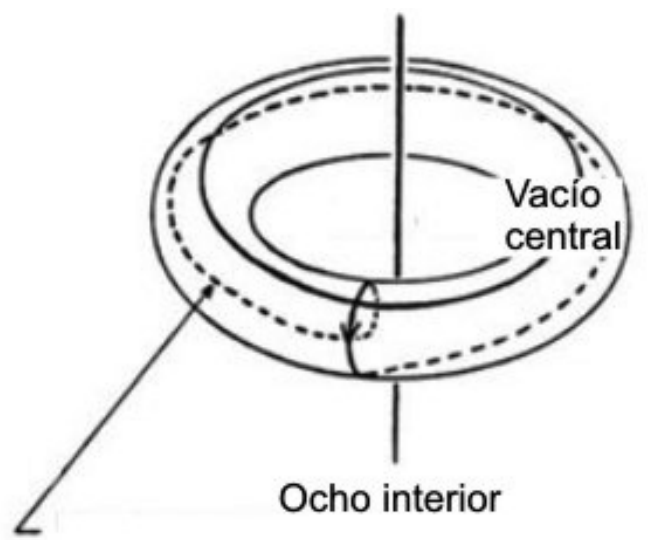

Vuelta por la demanda que cuente también la vuelta por el deseo en torno de la falta del Otro, aquí representada por el agujero central, y que la demanda recubría. La vía de la valentía en Lacan implica ir más allá del amor narcisista neurótico que Freud (1914) tematizó en Introducción del narcisismo: un amor que ya no demanda el reconocimiento del ser del otro. Que inscribe la castración del Otro y la imposible relación sexual. Un amor advertido de las ilusiones de completud y reclamo de ser Uno. No se trata de abundar en las ilusiones de la pasión amorosa, sino de estar advertidos de dicha ilusión. Una forma de amor que consienta la castración en vez de velarla para hacer existir la relación sexual que no hay. La valentía ante la castración implica el compromiso con el deseo sostenido desde la falta irreductible inscripta a cuenta del sujeto. Modo de transitar una relación con el otro que persevera en el deseo, pero apaciguada de las pasiones del ser, que demandan que resuelva la castración.

\section{Referencias}

Cavell, S. (1999). La búsqueda de la felicidad. La comedia de enredo matrimonial en Hollywood. Paidós.

Baumbach, N. (director). (2018). Marriage story [película]. Heyday Films; Netflix.

Cukor, G. (director). (1949). Adam's Rib [película]. Metro-Goldwyn-Mayer.

Freud, S. (1914). Introducción del narcisismo. Amorrortu.

Howard, M. (2014). Eat, Drink and Remarry: Confessions of a Serial Wife. Harlequin.

Ibsen, H. (director). (1879). Casa de muñecas [obra de teatro]. Teatro Real de Copenhague.

Lacan, J. (1959-1960). El Seminario, Libro VII, La ética del psicoanálisis. Paidós.

Lacan, J. (15 de enero de 1974). El Seminario, Libro 21, "Les non dupes errent”. Inédito.

Lacan, J. (1981). El Seminario Libro 20: Aún, Buenos Aires. Paidós.

Musachi, G. (2012). Mujeres en movimiento. Fondo de Cultura Económica.

Ritvo, J.B. (2019). El feminismo entre la política y el erotismo. Imago Agenda, (206). 
1 También es una cita al libro de Margo Howard Eat, drink and remarry. Confessions of a serial wife, en el que la autora relata los avatares amorosos de su vida

2 “El amor que aborda al ser ¿̇no surge de allí lo que hace del ser aquello que sólo se sostiene por errarse?” (Lacan, 1981, p. 176).

«La dimensión cómica está creada por la presencia en su centro de un significante oculto, pero que en la comedia antigua está ahí en persona: el falo. En la comedia lo que nos hace reír no es tanto el triunfo de la vida como su escape. (...) la vida escapa a todas las barreras que se le oponen. El falo es el significante de esa escapada. La vida pasa, triunfa de todos modos, pase lo que pase. El héroe cómico tropieza, se ve en apuros pero todavía vive. Lo tragicómico existe. Aquí yace la experiencia de la acción humana». Lacan (1959-1960, p. 373). 